\title{
O descarte do trabalhador idoso no capitalismo contemporâneo e sua reutilização: elementos que os conduzem ao mercado informal de trabalho
}

The discard of the elderly worker in contemporary capitalism and their reusability: elements leading to the informal labor market

\section{Cláudia Núbia dos Santos Alves*}

\begin{abstract}
Resumo - O estudo proposto nesse trabalho visa empreender uma discussão acerca do envelhecimento do trabalhador no capitalismo contemporâneo e as motivações que têm levado os trabalhadores idosos a se inserirem no mercado informal de trabalho.

Palavras-chave: envelhecimento; trabalho; informalidade.
\end{abstract}

Abstract - The study proposed in this paper aims to undertake a discussion about the aging of workers in contemporary capitalism and the motivations that have led older workers to enter the informal labor market.

Keywords: aging; labor; informality.

\section{Introdução}

O presente trabalho tem como objeto de estudo a "problemática social do envelhecimento" do trabalhador no capitalismo contemporâneo, tendo como tela de fundo as particularidades que revelam o retorno do trabalhador idoso ao mercado de trabalho.

Cabe ressaltar que a expressão "problemática social" da velhice ou do envelhecimento é utilizada sob aspas pois não se considera que o

* Assistente Social. Pós graduanda em Geriatria e Gerontologia pela CGESP. E-mail: nubiaas2016@outlook.com. ORCID: https://orcid.org/0000-0003-4968-4098. 


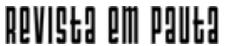

\} O DESCARTE DO TRABALHADOR IDOSO - ALVES, C. N. S. \}

DOI: $10.12957 /$ REP.2019.45224

envelhecimento ou a velhice pelas restrições físicas, nos papéis sociais, comportamental, dentre outros, seja um problema social para todos os idosos de uma população. Ao contrário, constitui um problema social para determinada classe destituída de propriedade, exceto da sua força de trabalho. Considerando-se sua vulnerabilidade em massa, essa classe, principalmente quando envelhece, perde o valor de uso para o capital (TEIXEIRA, 2008).

Desse modo, problematiza-se aqui o envelhecimento dos trabaIhadores destituídos dos meios de produção. Atenta-se a uma exposição do movimento do capital que é submetido às necessidades de acumulação e reprodução ampliada através do trabalho, buscando-se compreender de que modo a força de trabalho é expropriada e explorada pelo capital com o advento da aposentadoria.

Tendo em vista que a força de trabalho é o único bem de que o trabalhador dispõe para o capital, quando ele envelhece e se afasta do processo produtivo de mercadorias, cabe questionar: como tem vivenciado esse afastamento? Que elementos contribuem para o seu ingresso em uma nova jornada de trabalho? É por motivações econômicas ou subjetivas?

Dada a quantidade de trabalhos e suas variadas formas de abordagem, escolhemos estudar o emprego informal desenvolvido por idosos.

\section{Concepções acerca da velhice e do envelhecimento}

Para entendermos a questão do envelhecimento no Brasil, faz-se necessário perceber que este fenômeno é mundial e que nos anos mais recentes ganhou mais visibilidade nos países em desenvolvimento. Dados da ONU afirmam que, em 2050, pela primeira vez haverá mais idosos que crianças menores de 15 anos. Em 2012, já se estimava a população idosa em 810 milhões de pessoas com 60 anos ou mais, constituindo $11,5 \%$ da população global (IBGE, 2012).

A questão do crescimento da população idosa é apresentada por Veras (1999) como consequência do aumento da expectativa de vida e do declínio da taxa de fecundidade graças aos avanços da medicina. Com isso, a participação ascendente dos idosos demanda novos desafios para o Estado, governos, sociedade e família, no que se refere à necessária tomada de consciência da presença dos sujeitos sociais que podem e devem ser tratados enquanto cidadãos. Portanto, que merecem, como todos, dignidade, respeito e condições materiais que lhes permitam uma qualidade de vida digna.

Sobre a realidade estigmatizada dos idosos, Beauvoir (1990, p. 8) considera que "[...] essa sociedade não é apenas culpada, mas criminosa. Abrigada por trás do mito da expansão e da abundância, trata os velhos como párias". Por isso entende-se que nosso modelo societário impõe aos idosos estereótipos que nos conduzem, por meio de processos alienantes, a enxergar o velho como improdutivo, ultrapassado, que vive doente, entre 


\section{ReVIStg a d P p putt?}

\} O DESCARTE DO TRABALHADOR IDOSO - ALVES, C. N. S. \}

DOI: $10.12957 /$ REP.2019.45224

outros estigmas. Sendo assim, "[...] o caráter descartável do idoso é funcional a sociedade de consumo, reproduzindo, sem máscaras, as mazelas do capitalismo" (GOLDMAN, 2000, p. 19).

\subsection{O envelhecimento e o mundo do trabalho: limites e desafios}

As mutações no mundo do trabalho acarretaram consequências muito fortes no modo do trabalho operário. Vivemos, na década de 1970, um quadro de crise estrutural do capital, que fez com que o trabalhador adotasse estratégias de restauração do seu poder de reprodução e que afetaram diretamente o mundo do trabalho.

Com a sua expansão e a consequente crise do Welfare State ${ }^{1}$, o neoliberalismo passou a ditar o ideário dos programas a serem implementados pelos países capitalistas, contemplando reestruturação produtiva, privatizações, diminuição do poder estatal e desmonte dos direitos sociais dos trabalhadores. Para Antunes (1999, p. 179), dessa forma,

A centralidade do processo de reestruturação produtiva recai sobre a necessidade de recuperação do ciclo de reprodução do capital, no entanto foi ausente nesse processo o questionamento do modo de produção capitalista.

Particularmente nas últimas décadas, como respostas do capital à crise dos anos 1970, intensificaram-se as transformações no próprio processo produtivo. Isso aconteceu através do avanço tecnológico, da constituição das formas de acumulação flexível e dos modelos alternativos ao binômio taylorismo/fordismo, no qual se destaca, para o capital, especialmente o modelo "toyotista", ou modelo japonês.

As consequências das transformações do processo de produção no século XX, citadas por Antunes (1999), foram a diminuição do operariado manual, fabril, o aumento do trabalho parcial, o subcontratado, a terceirizado, a expansão dos assalariamentos médios e no setor de serviços, que inicialmente alimentou o desemprego tecnológico, bem como a exclusão dos trabalhadores jovens e dos mais velhos do mercado de trabalho nos países de capitalismo central.

Para enfrentar a crise e manter a lucratividade, o capital se reinventa, de modo a garantir a sua dinâmica de acumulação. Essas alterações atingem diretamente aqueles que, nas palavras de Antunes (1999), são a classe-que-vive-do-trabalho, operários, vendedores de serviços, todos os que não dispõem dos meios de produção.

${ }^{1}$ Consultar Esping-Andersen (1995). O futuro do Welfare State na nova ordem mundial. Lua Nova, n. 35, 1995. 


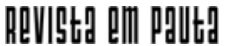

\} O DESCARTE DO TRABALHADOR IDOSO - ALVES, C. N. S. \}

DOI: $10.12957 /$ REP.2019.45224

Um traço marcante do processo de exploração da nova organização de produção é a captura da nossa subjetividade, em que é disseminada apenas a ideologia baseada em valores sociais econômicos capitalistas. Dessa maneira, o sujeito é obrigado a submeter-se a compreensões que fogem dos seus próprios desejos, se inscrevendo num campo puramente racional, embora possa assumir um caráter fantasioso quando assim interessar ao capital. São desejos reprimidos.

A subjetividade do trabalhador tornou-se fragmentada na atual sociedade sob o comando do capital. "A busca por pequenos gozos narcísicos", segundo Faria e Meneghetti apud Dejours (2000 p. 1), os novos modelos de produção e gestão, representados atualmente pelo toyotismo, e a disseminação de uma ideologia tipicamente alicerçada nos valores sociais e econômicos vinculados ao sistema de capital foram capazes de propiciar o sequestro da subjetividade do trabalhador. Consequentemente, levaramno a enfrentar, de forma mais resignada, o que Faria e Meneghetti apud Dejours (2000 p. 1) chama de condições físicas e psicológicas de trabalhos cada dia mais precários.

Mesmo apresentando todas essas condições, há uma verdadeira adesão e grande consenso acerca do trabalho defendido pelo modelo toyotista. O conceito empresa-família é entendido como uma extensão da sua casa, onde você deve sempre se dispor para garantir seu crescimento e lucratividade Atinge a consciência e subjetividade do trabalho e suas formas de representação, Como afirma César (2002, p. 9).

Sendo assim, o 'novo' caminho é a busca da 'adesão e do consentimento da classe trabalhadora' para as transformações do capital. Isto significa 'ganhar corações e mentes' dos trabalhadores, em uma nova forma de controle da força de trabalho: menos coercitivos e mais consensuais, cuja participação e parceria compõem a cultura da integração do trabalhador

\begin{abstract}
Além disso, assinala Teixeira (2008, p. 57):
o capitalismo através das práticas temporais, espaciais e do meios de produção, aloca e realoca o tempo de vida dos trabalhadores, ou o tempo social, redefinido pelas necessidades produtivas, ampliadas do capital, seja enquanto tempo de trabalho 'tempo livre' ou tempo de envelhecer.
\end{abstract}

Já de acordo com Mészáros (2002, p. 611),

'Os seres humanos [...] não podem ocupar, como seres humanos, seu lugar legitimo nas equações do capital, e muito menos ser considerados nos parâmetros do sistema do capital como a verdadeira finalidade de produção', ao contrário, '[...]submete toda a humanidade a finalidade da produção de riquezas', que não se converte em riqueza do gênero e desenvolvimento do indivíduo, pois o fim dessa lhe é estranho. 


\section{ReVIStg a d P p putt?}

\} O DESCARTE DO TRABALHADOR IDOSO - ALVES, C. N. S. \}

DOI: $10.12957 /$ REP.2019.45224

Dessa forma, a mão de obra declina rapidamente a partir do uso abusivo pelo capital, gerando pobreza para aqueles que não podem mais vender sua força de trabalho e não dispõem dos meios de subsistência. $O$ capital usa o tempo do trabalhador a seu critério, definindo o tempo de admissão e exclusão, entre eles a idade.

Assim, o tempo de vida do trabalhador continua sendo dominado, de forma opressiva, pelo capital, seja o tempo de trabalho dos integrados ou inseridos no mercado de trabalho, no qual não se suga somente suas forças físicas, mas também se captura sua subjetividade. (TEIXEIRA, 2008, p. 68).

Cabe ressaltar que, para "uma parcela ainda expressiva da nossa sociedade, o trabalho continuado, mesmo depois da aposentadoria, tem várias motivações" (NERI, 2009, p. 57). Entre os principais motivos, estão a necessidade de uma remuneração extra, o desejo de manter-se ativo ou questões relativas à honra. De fato, a sociedade burguesa não percebe o ser humano na sua subjetividade, mas como uma máquina produtiva e lucrativa, que quando não possui mais capacidades para gerar lucros é desvalorizada e deixada de lado. Portanto, o conteúdo valorativo do trabalho para os idosos está relacionado diretamente ao sentimento de pertença; já para o capital, ele está diretamente ligado à função lucrativa.

Diante da conjuntura social regida pela lógica mercantil, parar de trabalhar significa a perda do papel profissional, social e familiar. Essas perdas afastam o idoso da sociedade na qual ele está inserido.

É pelo trabalho que o homem se realiza como ser social; logo, quando esse trabalho cessa por questões de doença ou aposentadoria o idoso experimenta a "morte social". Moragas (1997) faz menção ao termo morte social do idoso ao comentar que esta pode existir em decorrência de um processo de internação em uma instituição, pelo fato de a mesma restringir os contatos sociais com o exterior e romper os seus laços sociais habituais. Logo, a sociedade capitalista se afasta do idoso, julgando-o como um ser impotente e improdutivo.

Em síntese, essa ambivalência existente entre os modos de envelhecer já se fazia perceptível desde o século XIX. Na atualidade, a problematização das condições de vida dos idosos apresenta as mesmas configurações, redefinidas apenas pelo recorte temporal.

\section{A centralidade da categoria trabalho}

Para entender o trabalho como categoria fundante do ser social, é necessário caracterizá-lo em termos ontológicos e explicitar de que forma ele se fundamenta na sociabilidade capitalista, na vida dos homens e das mulheres. A sociedade, através dos seus membros (homens e mulheres), 


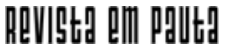

\} O DESCARTE DO TRABALHADOR IDOSO - ALVES, C. N. S. \}

DOI: $10.12957 /$ REP.2019.45224

transforma matérias naturais em produtos que atendem a suas necessidades. Essa transformação é realizada através de atividades que denominamos trabalho (NETTO; BRAZ, 2012).

Lukács (2013) foi o teórico que apresentou os aspectos mais importantes acerca do ser que vive em sociedade, apontando os principais traços que os distinguem dos outros animais e mostrando no trabalho o rompimento com o padrão de atividade meramente biológica.

Somente o trabalho tem, como sua essência ontológica, um claro caráter intermediário: ele é, essencialmente, uma interrelação entre homem (sociedade) e natureza, tanto inorgânica (utensílio, matéria-prima, objeto trabalho, etc.) como orgânica, inter-relação que pode até estar situada em pontos determinados da série a que nos referimos, mas antes de mais nada assinala a passagem, no homem que trabalha, do ser meramente biológico ao ser social. (LUKÁCS, 2013).

Na capacidade laborativa, o homem apresenta as principais características que o distinguem dos animais. Dessa forma, podemos dizer que o que diferencia o mundo dos homens da natureza são as relações sociais, as formas distintas e complexas de se relacionarem entre si. Com essa categoria, podemos entender de que forma o trabalho se caracteriza como uma atividade inteiramente inseparável do homem, expressando a capacidade de objetivar o seu pensamento, através da criação de objetos. "Somente o trabalho tem, como sua essência ontológica, um claro caráter de transição: ele é essencialmente, uma inter-relação entre homem (sociedade) e natureza [...]" (LUKÁCS, 2013, p. 44). Esse conjunto de elementos é fundamental para a reprodução das relações sociais.

Na sociedade capitalista, o trabalho já não se limita à finalidade imediata de outrora. Agora, ele se configura como um modo de exploração sem precedentes, em que a forma pela qual o trabalho se instala possibilita o desenvolvimento das capacidades humanas, das forças produtivas e das relações sociais, tornando a sociedade cada vez mais complexa e desenvolvida. O trabalhador experimenta o estranhamento do produto do seu trabalho e, assim, para que ele sobreviva é preciso que venda sua força de trabalho. Ao deixar de lado as suas necessidades humanas, o pensamento fetichista converte as próprias relações de produção em coisas.

Ao inserir-se num sistema estabelecido pela divisão social do trabalho, o ser social é desapropriado de sua condição ontológica para ser explorado enquanto produtor de valor-de-uso e valor-de-troca ${ }^{2}$, alienando-se e estranhando-se de sua própria condição humana genérica. É nesse sentido que "o trabalho estabelece a alienação, revelando o processo de coisificação da potencialidade humana.

Ao ingressar no mercado de trabalho, a força de trabalho passa a valer enquanto valor-de-troca, e as relações de trabalho passam a ser consideradas enquanto mercadoria. Nesse sentido, o envelhecimento do trabalhador 


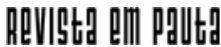

\} O DESCARTE DO TRABALHADOR IDOSO - ALVES, C. N. S. \}

DOI: $10.12957 /$ REP.2019.45224

no capitalismo contemporâneo apresenta-se como um fenômeno a ser desvelado em sua singularidade, universalidade e particularidade. No Brasil contemporâneo, as particularidades do envelhecimento se somam aos aspectos mundiais que envolvem o crescimento da população idosa.

\subsection{Precarização, informalidade e desemprego no capitalismo contemporâneo}

Segundo dados levantados pela Organização Internacional do Trabalho (OIT), o desemprego cai, mas as condições de trabalho não melhoram. (OIT, 2019). Atingimos uma fase do desenvolvimento histórico do sistema capitalista em que o desemprego é sua característica dominante (MÉSZÁROS, 2002).

Muitos acreditam que esse crescimento é resultado do processo de globalização. Desse modo, as transformações das forças produtivas, das relações de produção, dos sistemas institucionais e dos sistemas políticoideológicos formam o processo de globalização, que trouxe consigo o incremento de novas tecnologias e novas formas de organização. A capacidade tecnológica, denominada "automação industrial" e adotada pelas indústrias, coloca os operários hoje como profissionais responsáveis somente por inspecionar o trabalho das máquinas. Assim, instala-se uma nova forma de exploração pelo capital.

O desemprego estrutural é uma realidade da economia capitalista. Embora no Brasil os níveis de desemprego tenham se mostrado constantes, a produtividade do trabalho vem decaindo desde a década de 1980, em função de o crescimento do PIB ser menor que o nível de emprego. Os resultados do desemprego estrutural são nefastos e afetam toda a classe trabalhadora, como assinala Antunes (1999 p. 47),

Pode se dizer, de maneira sintética, que há uma processualidade contraditória que, de um lado, reduz o operariado industrial e fabril; de outro, aumenta o subproletariado, o trabalho precário e o assalariamento no setor de serviços. Incorpora o trabalho feminino e exclui os mais jovens e os mais velhos.

O desemprego trouxe consigo transformações no mundo do trabaIho e, embora esta seja uma realidade nos dias atuais, apresenta um caráter estratégico necessário para a criação de um exército de reserva. No seu texto Balanço do neoliberalismo, Anderson (2005) traz algumas considerações importantes sobre o neoliberalismo como sendo uma reação teóricoideológica e política contra o Estado intervencionista. Sobre isso, Hayek apud Anderson (1995) ainda argumenta que seria necessária a criação de um exército de reserva e uma dita saudável desigualdade para voltar a dinamizar a economia. Nessa conjuntura, é importante elucidar que, atualmente, 


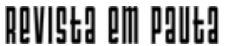

\} O DESCARTE DO TRABALHADOR IDOSO - ALVES, C. N. S. \}

DOI: $10.12957 /$ REP.2019.45224

"o que se verifica é a redução de empregos estáveis e protegidos, o que não significa o 'fim do trabalho' nem o 'fim da história' como afirma" (GUIRALDELLI apud POCHMANN, 2014, p89.).

Diferentemente do desemprego temporário e cíclico causado em períodos e conjunturas de crise do capital, o desemprego estrutural é caracterizado pela expulsão dos indivíduos da cadeia produtiva sem possibilidade de reinserção futura no mercado de trabalho. Ou, como diz Pochmann (2001, p. 89), é um "[...] desajuste entre a mão-de-obra demandada pelo processo de acumulação do capital e a mão-de-obra disponível no mercado de trabalho" (GUIRALDELLI apud POCHMANN, 2014).

No bojo desse movimento, sustenta-se um ideário de competência dos trabalhadores como resposta para atender aos interesses e às necessidades do capital, que se preocupa com resultados e não com processos. $\mathrm{Na}$ análise de Santana (2005), com o discurso da competência e a exigência de qualificação dos trabalhadores, cria-se o conceito de empregabilidade. Este consiste na capacidade de a força de trabalho se manter empregada ou encontrar novos empregos, o que, resumidamente, significa tornar-se empregável no mundo do trabalho mediante as atitudes e as competências dos trabalhadores.

Dessa maneira, a classe trabalhadora se fragmentou, heterogeneizou e complexificou ainda mais, criando trabalhadores precários e instáveis. Essas características se revelam em todos os seguimentos de trabaIhadores. Portanto, para Tavares (2002, p. 54):

Na medida em que o aumento da produtividade e a desregulamentação das relações de trabalho contribuem para a disponibilidade crescente da força de trabalho à procura de emprego e para fragilizar as negociações coletivas, o trabalho formal, estável, em tempo integral e socialmente protegido tende a ser uma categoria do passado.

De acordo com Tavares (2002), na sua obra Trabalho informal: os fios (in)visíveis da produção capitalista, o trabalho informal não é um fenômeno novo no mundo do trabalho, especialmente no Brasil, onde a dualidade e a heterogeneidade do mercado de trabalho são problemas históricoestruturais. Dados recentes mostram que o trabalho informal já representa 19,5\% de todas as ocupações nas principais cidades do Brasil, maior nível em oito anos (IBGE, 2015). Os dados ainda revelam que o trabalhador por conta própria é o típico homem de meia idade, com atividade de baixa e média renda. Ramos e Britto (2004, p. 8) argumentam que o crescimento da informalidade "representa um foco de preocupação em relação à perda de arrecadação tributária".

O Banco Mundial e o FMI, por sua vez, têm recomendado a expansão do setor informal como uma contratendência ao desemprego, que se coloca entre as ações complementares às políticas de proteção social para os extremamente pobres. $\mathrm{O}$ "setor informal" era visto como sinônimo 


\section{ReVIStg a d P puttg}

\} O DESCARTE DO TRABALHADOR IDOSO - ALVES, C. N. S. \}

DOI: $10.12957 /$ REP.2019.45224

de atraso, assim, o desenvolvimento do capital acabaria por eliminá-lo. Mas

quando a mesma economia de livre mercado se revela incapaz da integração prometida, o 'setor informal' é reivindicado, não porque o seu desempenho contribua de algum modo com a acumulação capitalista, mas como uma ação complementar à proteção social. (TAVARES, 2002, p. 55).

Nesse sentido, o capital assume a importante tarefa de esconder a essência, realçando a aparência e legitimando-a. Os recursos de informática e automação têm produzido uma grande maleabilidade na condução do trabalho na atualidade. Decorrendo da desregulamentação do trabalho, tendem a tornar o trabalho mais informal, contribuindo para que as fronteiras da relação capital/trabalho se tornem mais perceptíveis.

Com isso, torna-se evidente que pela deslocalização do trabalho negase a categoria tempo de trabalho e, por conseguinte, a subordinação do trabalho ao capital. Contudo, essa deslocalização, que os neoliberais traduzem como 'independência', apenas cria a ilusão de que o trabalhador adquiriu autonomia, simplesmente porque não sai de casa e não sofre uma vigilância direta, como ocorre na empresa. (TAVARES, 2002, p. 55).

A participação dos decrépitos na dinâmica de deslocalização do trabalho impulsionada pelas necessidades econômicas tem provocado a ilusão da autonomia do trabalho em suas trajetórias. Dessa forma, há uma falsa autonomia do trabalhador, de modo que cresce o desasslariamento e a precariedade, em que o tempo de trabalho socialmente necessário continua sendo determinante.

A problemática do envelhecimento também é resultado das diferenças de classe. Sua posição na hierarquia social é um fator preponderante para determinar de que maneira a velhice irá se manifestar. É crescente também o número de mulheres que, com o advento da aposentadoria, cada vez mais vêm assumindo o lado invisível do trabalho. Em decorrência da inutilidade ao trabalho, acabam assumindo um papel de solidariedade financeira, tomando o posto tradicionalmente masculino, como avós chefes de família e provedoras. Até mesmo executam papel de cuidadoras dos netos ou dos membros vulneráveis da família. Em geral, estas aparecem muito mais engajadas em fluxos de apoio do que os homens, o que costuma ser atribuído não só às suas maiores necessidades financeiras, mas também ao fato de serem elas mais apegadas emocionalmente aos filhos.

O capital transforma o tempo de vida do trabalhador para a valorização e o acúmulo. O tempo de envelhecer é transformado em tempo de consumo manipulado de bens e serviços para aqueles idosos que detêm melhores condições de renda. 


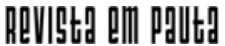

\} O DESCARTE DO TRABALHADOR IDOSO - ALVES, C. N. S. \}

DOI: $10.12957 /$ REP.2019.45224

\section{Considerações finais}

A grande questão levantada nesse trabalho buscou compreender as particularidades do envelhecimento do trabalhador na contemporaneidade. Para tanto, centralizou-se a análise na perspectiva de desvendar os elementos constituintes da problemática social do envelhecimento para os trabalhadores submetidos à exigência de vender sua força de trabalho para a sua sobrevivência. De forma geral, o objetivo foi constatar como se dá o tempo de vida do trabalhador regido pelo tempo da mercadoria. É a esse tempo que ele precisa se submeter mesmo depois da aposentadoria, agora com uma nova roupagem, traduzido no trabalho informal.

Tendo em vista as análises desenvolvidas até aqui, a primeira conclusão a que se chega é que as discussões associadas ao envelhecimento na atualidade se acirraram a partir dos anos 1990 e acabaram por delinear questões que essencialmente estão além da degradação física e da desvalorização social.

Tendo em vista que, para o capital, a força de trabalho é um dos fatores determinantes para a sua valorização, o trabalhador envelhecido por conta da idade biológica e da espoliação das suas capacidades físicas é retirado do mundo do trabalho produtivo. Em decorrência das necessidades materiais e da redução do valor dos benefícios, esses idosos têm sido obrigados a buscar novas formas de subsistência, nas quais a falta de um acréscimo no valor de sua aposentadoria tem caracterizado para eles as restrições ao acesso a bens e serviços básicos para a subsistência, agravando as dificuldades e limitações inerentes à velhice.

Nesse sentido, afastado completamente do trabalho, agrava-se ainda mais sua condição de dependência. Envelhecer, para o trabalhador nos ditames do capital, traz não apenas questões econômicas, como também de valores subjetivos e culturais. Verifica-se então que, ao assumir os postos de trabalho informal, o idoso continua a ser explorado pelo capital, sem vínculo empregatício formal. Sua atuação se converge numa atividade lucrativa para o capital como instrumento meramente quantitativo, mas carregada de valor para o trabalhador que a executa, em que aquele que não se encontra inserido no mercado de trabalho formal enfrenta todo tipo de estigma social.

Outro ponto importante destacado nesse trabalho se revela à medida que, quando não atua diretamente como produtor de valor-de-uso/ valor-de-troca, o trabalhador passa a assumir o papel de consumidor de mercadorias, com desejos e necessidades pré-estabelecidos pelo capital. Nessa perspectiva, é notório que os idosos sujeitos desse estudo, inseridos numa relação de retorno ao trabalho, não reconhecem os elementos negativos que constituem esse processo. Assim, os motivos de retornarem ao trabalho se diversificam em torno de um elemento central, que é o capitalismo e suas formas de atuação, seja de cunho subjetivo, econômico ou so- 


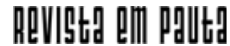

\} O DESCARTE DO TRABALHADOR IDOSO - ALVES, C. N. S. \}

DOI: 10.12957/REP.2019.45224

cial. Vai desde a complementação da renda até a valorização pessoal, passando pela função valorativa que o trabalho representa na sociedade capitalista.

Diante do exposto, o trabalho precisa ser uma opção frente a tantas outras possibilidades de realização pessoal para aqueles que, pelo curso normal da vida, deveriam estar desfrutando da velhice e do descanso. 


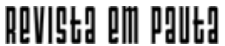

\} O DESCARTE DO TRABALHADOR IDOSO - ALVES, C. N. S. \}

DOI: $10.12957 /$ REP.2019.45224

\section{Referências}

ANDERSON, P. Balanço do neoliberalismo. (In SADER, Emir \& GENTILI, Pablo (orgs.) Pós-neoliberalismo: as políticas sociais e o Estado democrático. Rio de Janeiro: Paz e Terra,1995).

ANTUNES, R. Os sentidos do trabalho. São Paulo: Boitempo, 1999.

BEAUVOIR, S. A velhice. Rio de Janeiro: Nova Fronteira, 1990.

BRASIL, IBGE. Síntese de Indicadores Sociais: Uma análise das condições de vida da população brasileira 2008. Rio de Janeiro, 2008.

CÉSAR, M. de J. Responsabilidade social: novo ethos do discurso empresarial Juiz de Fora. Anais do XI Encontro Nacional de Pesquisadores em Serviço Social, 2002.

DEJOURS, C. A Loucura do Trabalho. Estudo de Psicopatologia do Trabalho. São Paulo. CORTEZ, 1987.

GOLDMAN, S. N. Velhice e Direitos Sociais. In: PAZ, Serafim PAZ et al, (org). Envelhecer com Cidadania: Quem sabe um dia? Rio de Janeiro: ANG; CBCISS, 2000, p.12-42.

GUIRALDELLI, R. Trabalho, trabalhadores e questão social na sociabilidade capitalista. Cadernos de PSICOLOGIA Social do Trabalho. Vol., no.1. São Paulo. 2014.

LESSA, S. A centralidade ontológica do trabalho em Lukács. Serviço Social e Sociedade, São Paulo, n. 52, 1996.

LUKÁCS, G. Para uma ontologia do ser social. São Paulo: Boitempo, 2013. MÉSZÁROS, I. Para além do capital. São Paulo: Boitempo, 2002.

MORAGAS, R. M. Gerontologia social: envelhecimento e qualidade de vida. São Paulo: Paulinas, 1997.

NERI, A. A O Envelhecimento no Universo do Trabalho Desafios e Oportunidades depois dos 50anos. IN: Júnior, Juarez Correia Barros/ organizador. Empreendedorismo, Trabalho e Qualidade de Vida na Terceira Idade 1. Ed/ São Paulo: Ed. Edicon. 2009.

NETTO, J. P.; BRAZ, M. Economia política: uma introdução crítica. São Paulo: Cortez, 2012.

POCHMANN, M. O emprego na globalização: a nova divisão internacional do trabalho e os caminhos que o Brasil escolheu. São Paulo: Boitempo, 2001.

RAMOS, L. BRITTO, M. O funcionamento do mercado de trabalho metropolitano brasileiro no período 1991- 2002: tendências, fatos estilizados e mudanças estruturais, IPEA, 2004 


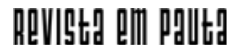

\} O DESCARTE DO TRABALHADOR IDOSO - ALVES, C. N. S. \}

DOI: 10.12957/REP.2019.45224

SANTANA, M. A. O mundo do trabalho em mutação: as reconfigurações e seus impactos. Cadernos IHU Idéias, 3(34), 1-22. São Leopoldo, 2005

TAVARES, M. A. Trabalho informal: os fios (in)visíveis da produção capitalista. Revista Outubro, n. 7, 2002.

TEIXEIRA, S. M. Envelhecimento e trabalho no tempo do capital: implicações para a proteção social no Brasil/Solange Maria Teixeira. São Paulo: Cortez, 2008.

VERAS, R. P. O Brasil Envelhecido e Preconceito Social. In: (Org) Terceira Idade:Alternativas para uma sociedade em Transição. Rio de Janeiro: Relume - Dumará: UERJ, UNATI, 1999.

DOI: $10.12957 /$ rep.2019.45224

Recebido em 19 de dezembro de 2017.

Aprovado para publicação em 30 de maio de 2018.

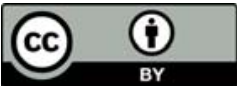

A Revista Em Pauta: Teoria Social e Realidade Contemporânea está licenciada com uma Licença Creative Commons Atribuição 4.0 Internacional. 